\title{
Development of KSTAR ECE imaging system for measurement of temperature fluctuations and edge density fluctuations
}

Citation for published version (APA):

Yun, G. S., Lee, W., Choi, M. J., Kim, J. B., Park, H. K., Domier, C. W., Tobias, B. J., Liang, T., Kong, X., Luhmann, N. C., \& Donné, A. J. H. (2010). Development of KSTAR ECCE imaging system for measurement of temperature fluctuations and edge density fluctuations. Review of Scientific Instruments, 81(10), 10D930-1/3. [10D930]. https://doi.org/10.1063/1.3483209

DOI:

$10.1063 / 1.3483209$

Document status and date:

Published: 01/01/2010

Document Version:

Publisher's PDF, also known as Version of Record (includes final page, issue and volume numbers)

\section{Please check the document version of this publication:}

- A submitted manuscript is the version of the article upon submission and before peer-review. There can be important differences between the submitted version and the official published version of record. People interested in the research are advised to contact the author for the final version of the publication, or visit the $\mathrm{DOI}$ to the publisher's website.

- The final author version and the galley proof are versions of the publication after peer review.

- The final published version features the final layout of the paper including the volume, issue and page numbers.

Link to publication

\footnotetext{
General rights

- You may freely distribute the URL identifying the publication in the public portal. follow below link for the End User Agreement:

www.tue.nl/taverne

Take down policy

If you believe that this document breaches copyright please contact us at:

openaccess@tue.nl

providing details and we will investigate your claim.
}

Copyright and moral rights for the publications made accessible in the public portal are retained by the authors and/or other copyright owners and it is a condition of accessing publications that users recognise and abide by the legal requirements associated with these rights.

- Users may download and print one copy of any publication from the public portal for the purpose of private study or research.

- You may not further distribute the material or use it for any profit-making activity or commercial gain

If the publication is distributed under the terms of Article $25 \mathrm{fa}$ of the Dutch Copyright Act, indicated by the "Taverne" license above, please 


\title{
Development of KSTAR ECE imaging system for measurement of temperature fluctuations and edge density fluctuations ${ }^{a)}$
}

\author{
G. S. Yun, ${ }^{1, b)}$ W. Lee, ${ }^{1}$ M. J. Choi, ${ }^{1}$ J. B. Kim, ${ }^{1}$ H. K. Park, ${ }^{1}$ C. W. Domier ${ }^{2}$ B. Tobias,${ }^{2}$ \\ T. Liang, ${ }^{2}$ X. Kong, ${ }^{2}$ N. C. Luhmann, Jr., ${ }^{2}$ and A. J. H. Donné ${ }^{3}$ \\ ${ }^{1}$ Pohang University of Science and Technology, Pohang, Gyungbuk 790-784, South Korea \\ ${ }^{2}$ University of California, Davis, California 95616, USA \\ ${ }^{3}$ FOM Institute for Plasma Physics Rijnhuizen, 3430 BE Nieuwegein, The Netherlands
}

(Presented 18 May 2010; received 16 May 2010; accepted 19 July 2010; published online 28 October 2010)

\begin{abstract}
The ECE imaging (ECEI) diagnostic tested on the TEXTOR tokamak revealed the sawtooth reconnection physics in unprecedented detail, including the first observation of high-field-side crash and collective heat transport [H. K. Park, N. C. Luhmann, Jr., A. J. H. Donné et al., Phys. Rev. Lett. 96, 195003 (2006)]. An improved ECEI system capable of visualizing both high- and low-field sides simultaneously with considerably better spatial coverage has been developed for the KSTAR tokamak in order to capture the full picture of core MHD dynamics. Direct 2D imaging of other MHD phenomena such as tearing modes, edge localized modes, and even Alfvén eigenmodes is expected to be feasible. Use of ECE images of the optically thin edge region to recover $2 \mathrm{D}$ electron density changes during $\mathrm{L} / \mathrm{H}$ mode transitions is also envisioned, providing powerful information about the underlying physics. The influence of density fluctuations on optically thin ECE is discussed. (C) 2010 American Institute of Physics. [doi:10.1063/1.3483209]
\end{abstract}

\section{INTRODUCTION}

Electron cyclotron emission (ECE) radiometry is a well established diagnostic technique for measuring electron temperature $\left(T_{e}\right)$ of tokamak plasmas. ${ }^{1,2}$ The cyclotron resonance frequency is inversely proportional to the major radius of tokamak plasma and, for optically thick plasma, the radiation temperature $\left(T_{*}\right)$ at the cyclotron resonance equals the electron temperature, providing direct information on local electron temperature. The conventional ECE radiometers have been widely used for monitoring $1 \mathrm{D}$ radial $T_{e}$ profiles.

However, 2D localized imaging measurements, as opposed to the traditional 1D or chordal tomographic images, are considered essential for the physics study of complex behaviors such as MHD instabilities and waves in the tokamak plasmas. Recently, 2D visualization of sawtooth crash via an ECE imaging system in the TEXTOR tokamak revealed the physics of sawtooth phenomena ${ }^{3}$ in unprecedented detail including the unexpected high-field side crash, ${ }^{4}$ challenging the existing theoretical models. ${ }^{5-7}$

The ECE imaging (ECEI) system is essentially an array of radiometers optically imaged onto the plane of the poloidal cross section of the tokamak plasma. After demonstrating the powerful capabilities as $2 \mathrm{D}$ local $T_{e}$ diagnostic, ECEI systems with improved rf electronics and imaging optics have been launched in other major tokamaks including ASDEX-U ${ }^{8}$ and DIII-D. ${ }^{9}$ These ECEI systems have provided

\footnotetext{
${ }^{\text {a) }}$ Contributed paper, published as part of the Proceedings of the 18th Topical Conference on High-Temperature Plasma Diagnostics, Wildwood, New Jersey, May 2010.

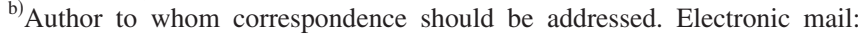
gunsu@postech.ac.kr.
}

invaluable 2D images of MHD phenomena such as tearing modes, edge localized modes, and Alfvén eigenmodes as well as sawtooth crashes. It should be noted that the ECEI systems have been focused on $T_{e}$ fluctuation measurements rather than absolute $T_{e}$ profile measurements partially due to the difficulty of absolute calibration.

This paper describes a further improved ECEI system ready to be launched for the 2010 KSTAR operation. The KSTAR ECEI system is capable of visualizing both highand low-field sides simultaneously with considerably wider spatial coverage (up to $90 \mathrm{~cm}$ vertical span). These capabilities will enable capturing the full picture of core MHD dynamics during sawtooth crash for the first time. ECE radiation temperature no longer equals the local $T_{e}$ for optically thin region, especially the plasma edge. Optical thickness effect on $T_{e}$ fluctuation measurements and the feasibility of extracting density fluctuation information from optically thin ECE are also discussed.

\section{KSTAR ECEI SYSTEM}

The KSTAR ECEI system is schematically shown in Fig. 1. The system design is aimed at visualizing both high-field side (HFS) and low-field side (LFS) simultaneously with wide vertical coverage up to $90 \mathrm{~cm}$ for $2 \mathrm{~T}$ operation. The basic components of the system are similar to the ASDEX-U and DIII-D ECEI systems, namely, (1) vacuum viewport window, (2) imaging optics for optically coupling the ECE radiation $(\sim 100 \mathrm{GHz})$ to antenna array, (3) antenna/mixer array, (4) heterodyne-mixing local oscillator (LO) for downconverting ECE rf signals to intermediate frequencies (IF) (bandwidth $\sim 10 \mathrm{GHz}$ ), (5) IF circuit boards for splitting and down-converting the IF signals into eight frequency bands 


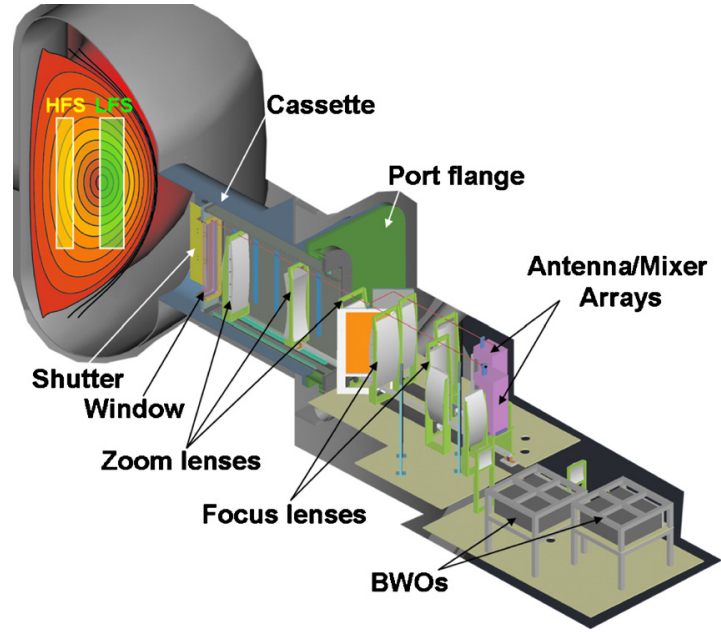

FIG. 1. (Color online) KSTAR ECEI system. Approximate sight areas are indicated in the inset plasma image, illustrating simultaneous coverage of LFS and HFS. Zoom lenses are placed in close proximity to the plasmas through the long port cassette to maximize the optical throughput of the ECE radiation into the dual antenna arrays. Frequency tunable BWOs are optically coupled to the arrays. IF/video circuits and data acquisition subsystems are not shown.

corresponding to eight radial locations in the plasma, (6) video circuit boards for integrating the second stage IF signals (bandwidth of $\sim 0.6 \mathrm{GHz}$ each), and (7) digitization system.

The KSTAR tokamak offers long cassette-type ports for midplane diagnostics, which can be a significant advantage for diagnostics requiring wide sight angle and proximity access to the plasma. A fused silica vacuum viewport window is attached at the inner end of the ECEI cassette $(\sim 1.4 \mathrm{~m}$ long, $\sim 0.3 \mathrm{~m}$ wide). The window is $\sim 760 \times 200 \mathrm{~mm}^{2}$ rectangular, $30 \mathrm{~mm}$ thick, and vacuum sealed by double Viton O-rings. The extra large window size is necessary for wide vertical coverage without diffraction effect. The large thickness is chosen to ensure safety under mechanical and thermal stresses during both vessel baking and normal operation. The thick window suffers a transmittance modulation of $\sim 65 \%-100 \%$ in the $\sim 2.5 \mathrm{GHz}$ range due to the etalon effect. However, the etalon effect can be factored out for $T_{e}$ fluctuation measurements since it is approximately independent of incident angles and polarizations for small incident angles. The window is rotated by $3^{\circ}$ in the horizontal direction to minimize the standing wave effect between the window and the zoom lens next to the window. A shutter is installed on the window to prevent deposition due to wall conditioning and protect the system in case of large stray electron cyclotron heating or neutral beam injection powers.

The KSTAR ECEI system features a highly flexible imaging optics based on the Cooke triplet concept ${ }^{10}$ for the zoom control. The imaging optics is designed to fully utilize the long cassette which enables proximity access to the plasma. The zoom optics achieves a wide vertical zoom range $(\sim 30-90 \mathrm{~cm})$ covering the entire vertical span of the plasma. The focus lenses form the image of the antenna array onto the radial region corresponding to the selected LO frequency in order to maximize the coupling between the antenna array and the plasma ECE radiation. The Cooke triplet

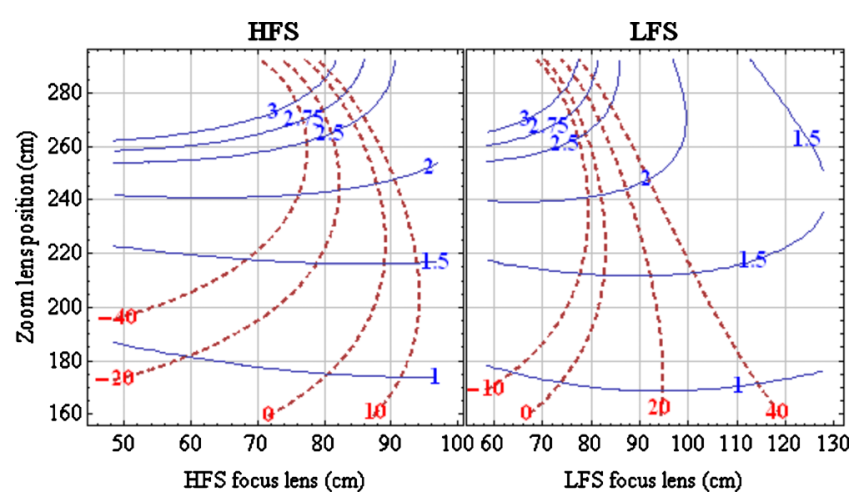

FIG. 2. (Color online) Zoom and focus controls. Contours of zoom factors (blue solid lines) and contours of focus positions from the plasma center (red dashed lines; inboard direction being negative) are shown as a function of zoom and focus lens positions. Contours are calculated based on paraxial Gaussian beam analysis.

design enables approximately independent control of zoom and focus as shown in Fig. 2, making the lens position control much simpler. Further details of the imaging optics design can be found elsewhere. ${ }^{11}$

Two antenna/mixer arrays are used for simultaneous coverage of LFS and HFS. Each array is enclosed in a modular box and has 24 vertical channels, four more channels compared to the DIII-D system but otherwise identical. The LO mixing is achieved using frequency tunable backward oscillators (BWOs) (ELVA-1 models G4-143e and G4-143f) located close to the array boxes. The BWO power is optically delivered through the free space using lenses instead of waveguides, which is expected to result in less LO power loss. The BWOs are chosen for wider frequency range and flexible frequency control compared to fixed frequency Gunn-oscillators. The BWO output has a slight frequency instability of less than $0.05 \%$ and power modulation of less than $0.5 \mathrm{~dB}$ at $60 \mathrm{~Hz}$ (the $220 \mathrm{~V}$ utility line frequency), which is tolerable for measurements of MHD activities. However, using an array of high power fixed frequency oscillators combined with frequency doubler/tripler instead of BWOs seems favorable for $3 \mathrm{~T}$ or higher operation partially because no BWO source is available for frequency $>170 \mathrm{GHz}$.

The IF/video components are identical to the DIII-D system. The video bandwidth is selectable up to $400 \mathrm{kHz}$, corresponding to the temperature resolution $\delta T_{e} / T_{e}$ $=\sqrt{\Delta f_{\mathrm{IF}} / \Delta f_{\text {video }}} \approx 3 \%$, where $\Delta f$ indicates bandwidth. Technical details on antenna design and IF/video circuits are discussed in detail by Domier et al. ${ }^{9,12,13}$

The KSTAR ECEI system has 24 vertical $\times 8$ radial channels in each array, which add up to 384 total number of channels. Digitization of this large number channels at least twice as fast as the video bandwidth $(\sim 400 \mathrm{kHz})$ requires high speed digitizers $(\sim 1 \mathrm{MHz})$ and results in high data volume $\sim 5$ Gbyte per typical 5 s operation. Digitization and large volume data handling schemes are discussed in detail elsewhere. $^{14}$

Advancements in microwave antenna design, LO coupling, and zoom optics in the DIII-D ECEI system have led to a significant improvement in signal quality compared to its 
predecessors, TEXTOR and ASDEX-U systems, and the importance of clean signal has been demonstrated in the initial data. ${ }^{9}$ The KSTAR ECEI system benefits from the same microwave technology. In addition, the flexible zoom control and accurate focus control will result in wider plasma coverage and further improved signal-to-noise ratio.

\section{APPLICATION OF ECEI ON EDGE PLASMA PHYSICS}

For the optically thin region of the plasma, ECE spectral intensity becomes a complex function of $T_{e}, n_{e}$, and wall reflection. ${ }^{1}$ In such cases care must be taken for interpretation of ECEI data because $T_{*}(\omega)$ no longer equals $T_{e}$ at the resonance position $r_{\omega=n \omega_{c}}$. Peters et al. ${ }^{15}$ compared several validity criteria for estimating various forms of $T_{e}$ with $15 \%$ accuracy in terms of the optical thickness $\tau$ :

$$
\begin{aligned}
& \tilde{T}_{e} /\left\langle T_{e}\right\rangle \text { by } \widetilde{T}_{*} /\left\langle T_{*}\right\rangle \Rightarrow \text { requires } \tau>1.0, \\
& \left\langle T_{e}\right\rangle \text { by }\left\langle T_{*}\right\rangle \Rightarrow \text { requires } \tau>0.8, \\
& \tilde{T}_{e} \text { by } \tilde{T}_{*} \Rightarrow \text { requires } \tau>0.23,
\end{aligned}
$$

where $\widetilde{T}$ represents fluctuating quantity and $\langle T\rangle$ represents time-averaged quantity. Reflection coefficient $(r)$ of a typical vessel wall $\sim 0.8$, Maxwellian electron distribution, and small density fluctuation $\left(\tilde{n}_{e}\right)$ are assumed in the derivation. The first case corresponds to the usual ECEI data scaling scheme and the second case corresponds to the usual profile measurements using ECE radiometer. The third case corresponds to absolute fluctuation measurements. The last two cases are rarely applicable for ECEI data because of the difficulty in absolute calibration.

Further consideration is required to take into account the density effect for the plasma edge region, where $\tilde{n}_{e} /\left\langle n_{e}\right\rangle$ is presumably much larger than $\widetilde{T}_{e} /\left\langle T_{e}\right\rangle$. The underlying equations for the above criteria are

$$
\begin{aligned}
& \left\langle T_{*}\right\rangle=A_{1}\left\langle T_{e}\right\rangle, \\
& \frac{\widetilde{T}_{*}}{\left\langle T_{*}\right\rangle}=\left(1+A_{2}\right) \frac{\widetilde{T}_{e}}{\left\langle T_{e}\right\rangle}+A_{2} \frac{\tilde{n}_{e}}{\left\langle n_{e}\right\rangle},
\end{aligned}
$$

where $A_{1}=\left(1-e^{-\tau}\right) /\left(1-r e^{-\tau}\right) \quad$ and $\quad A_{2}=\left(1-r A_{1}\right) \cdot \tau e^{-\tau} /(1$ $\left.-e^{-\tau}\right)$. For nominal wall reflection coefficient $r \lessgtr 0.8$ and $\tau$ $\ll 1, A_{2} \approx 1-\tau(1+r) / 2(1-r) \approx 1$ and Eq. (5) becomes

$$
\frac{\tilde{T}_{*}}{\left\langle T_{*}\right\rangle} \approx 2 \frac{\widetilde{T}_{e}}{\left\langle T_{e}\right\rangle}+\frac{\tilde{n}_{e}}{\left\langle n_{e}\right\rangle} .
$$

Thus, if $\tilde{n}_{e} /\left\langle n_{e}\right\rangle \gg 2 \widetilde{T}_{e} /\left\langle T_{e}\right\rangle$, the radiometer signal should be interpreted as density perturbations.

Consider the case that a preliminary information on the optical thickness, the wall reflection coefficient, and the level of $\widetilde{T}_{e} /\left\langle T_{e}\right\rangle$ is available. If the assumed $T_{e}$ fluctuation level is too small to account the measurement $\widetilde{T}_{*} /\left\langle T_{*}\right\rangle$ according to Eq. (5), the density term must be dominant and the density fluctuation level can be estimated as $\tilde{n}_{e} /\left\langle n_{e}\right\rangle=\widetilde{T}_{*} /\left\langle T_{*}\right\rangle / A_{2}$. Thus, under favorable conditions similar to this example, $2 \mathrm{D}$ ECEI images of the optically thin edge region can be used to recover the edge plasma physics such as electron density changes during $\mathrm{L} / \mathrm{H}$ mode transitions.

\section{SUMMARY AND UPGRADE PLANS}

The combination of highly flexible imaging optics and advanced microwave technology used in the KSTAR ECEI system will enable high quality 2D imaging of various MHD activities such as sawteeth, tearing modes, edge localized modes, and Alfvén eigenmodes. For certain cases, ECEI images of the optically thin plasma edge region can be interpreted as density perturbations, providing valuable information on edge plasma physics. Future upgrades are planned for KSTAR high-field operation $(\geq 3 \mathrm{~T})$ and second ECEI system combined with multifrequency imaging reflectometry ${ }^{16,17}$ for the 2012 operation.

\section{ACKNOWLEDGMENTS}

This work was supported by NRF of Korea under Contract No. 20090082507, UC Davis, and the association EURATOM-FOM.

${ }^{1}$ I. H. Hutchinson, Principles of Plasma Diagnostics, 2nd ed. (Cambridge University Press, New York, NY, 2002).

${ }^{2}$ M. Bonaciti, R. Cano, O. De Barbieri, and F. Engelmann, Nucl. Fusion 23, 1153 (1983)

${ }^{3}$ S. von Goeler, W. Stodiek, and N. Sauthoff, Phys. Rev. Lett. 33, 1201 (1974).

${ }^{4}$ H. K. Park, N. C. Luhmann, Jr., A. J. H. Donné, I. G. J. Classen, C. W. Domier, E. Mazzucato, T. Munsat, M. J. van de Pol, and Z. Xia, Phys. Rev. Lett. 96, 195003 (2006).

${ }^{5}$ B. B. Kadomtsev, Sov. J. Plasma Phys. 1, 389 (1975).

${ }^{6}$ J. A. Wesson, Plasma Phys. Controlled Fusion 28, 243 (1986).

${ }^{7}$ Y. Nagayama, M. Yamada, W. Park, E. D. Fredrickson, A. C. Janos, K. M. McGuire, and G. Taylor, Phys. Plasmas 3, 1647 (1996).

${ }^{8}$ I. G. J. Classen, J. E. Boom, W. Suttrop, E. Schmid, B. Tobias, C. W. Domier, N. C. Luhmann, Jr., A. J. H. Donné, R. J. E. Jaspers, P. C. de Vries, H. K. Park, T. Munsat, M. Garcia-Munoz, and P. A. Schneider, Rev. Sci. Instrum. 81, 10D929 (2010).

${ }^{9}$ B. Tobias, C. W. Domier, T. Liang, X. Kong, L. Yu, G. S. Yun, H. K. Park, I. G. J. Classen, J. E. Boom, A. J. H. Donné, T. Munsat, R. Nazikian, M. Van ZeelandR. L. Boivin, and N. C. Luhmann, Jr., Rev. Sci. Instrum. 81, 10D928 (2010).

${ }^{10}$ M. J. Kidger, Fundamental Optical Design (SPIE, Bellingham, WA, 2001).

${ }^{11}$ T. Liang, B. Tobias, X. Kong, C. W. Domier, N. C. Luhmann, Jr., W. Lee, G. S. Yun, and H. K. Park, Rev. Sci. Instrum. 81, 10D909 (2010).

${ }^{12}$ C. Domier, Z. G. Xia, P. Zhang, N. C. .Luhmann, H. K. Park, E. Mazzucato, M. J. van de Pol, I. G. J. Classen, A. J. H. Donné, and R. Jaspers, Rev. Sci. Instrum. 77, 10E924 (2006).

${ }^{13}$ P. Zhang, C. W. Domier, T. Liang, X. Kong, B. Tobias, Z. Shen, N. C. Luhmann, H. Park, I. G. J. Classen, M. J. van de Pol, A. J. H. Donné, and R. Jaspers, Rev. Sci. Instrum. 79, 10F103 (2008).

${ }^{14}$ J. B. Kim, W. Lee, G. S. Yun, H. K. Park, C. W. Domier, and N. C. Luhmann, Jr., Rev. Sci. Instrum. 81, 10D931 (2010).

${ }^{15}$ M. Peters, G. Gorini, and P. Mantica, Nucl. Fusion 35, 873 (1995).

${ }^{16}$ H. K. Park, I. Hong, M. Kim, G. S. Yun, W. Lee, J. Kim, B. Tobias, C. W. Domier, N. C. Luhmann, Jr., and K. W. Kim, Rev. Sci. Instrum. 81, 10D933 (2010).

${ }^{17}$ W. Lee, G. S. Yun, Y. Nam, I. Hong, J. B. Kim, H. K. Park, B. Tobias, T. Liang, C. W. Domier, and N. C. Luhmann, Jr., Rev. Sci. Instrum. 81, 10D932 (2010). 